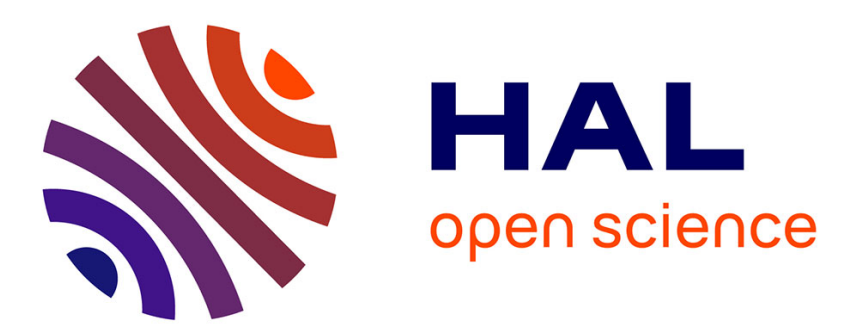

\title{
Alcoholysis catalyzed by Candida antarctica lipase B in a gas/solid system : effects of water on kinetic parameters
}

Marianne Graber, Marie-Pierre Bousquet-Dubouch, Sylvain Lamare, Marie-Dominique Legoy

\section{- To cite this version:}

Marianne Graber, Marie-Pierre Bousquet-Dubouch, Sylvain Lamare, Marie-Dominique Legoy. Alcoholysis catalyzed by Candida antarctica lipase B in a gas/solid system: effects of water on kinetic parameters. Biochimica et Biophysica Acta Proteins and Proteomics, 2003, 1648, pp.24-32. hal00329680

\section{HAL Id: hal-00329680 \\ https://hal.science/hal-00329680}

Submitted on 13 Oct 2008

HAL is a multi-disciplinary open access archive for the deposit and dissemination of scientific research documents, whether they are published or not. The documents may come from teaching and research institutions in France or abroad, or from public or private research centers.
L'archive ouverte pluridisciplinaire HAL, est destinée au dépôt et à la diffusion de documents scientifiques de niveau recherche, publiés ou non, émanant des établissements d'enseignement et de recherche français ou étrangers, des laboratoires publics ou privés. 
Alcoholysis catalyzed by Candida antarctica lipase B in a gas/solid system : effects of water on kinetic parameters

Marianne Graber, Marie-Pierre Bousquet-Dubouch, Sylvain Lamare and MarieDominique Legoy

Université de la Rochelle, Laboratoire de Génie Protéique et Cellulaire, Pôle Sciences et Technologies, Bâtiment Marie Curie, Avenue Michel Crépeau, 17042 La Rochelle, Cedex 1, France

Foot note : Corresponding author : Dr. Marianne Graber, fax: 33546458265 , Email:mgraber@univ-lr.fr

\section{KEY WORDS}

Lipase B from Candida antarctica - kinetics - transesterification - water - solid/gas biocatalysis - hydration 


\section{ABSTRACT}

The influence of water on the kinetics of alcoholysis of methyl propionate and $n$-propanol catalyzed by immobilized lipase B from Candida antarctica was studied in a continuous solid/gas reactor. In this reactor, the solid phase is composed of a packed enzymatic sample which is percolated by gaseous nitrogen, simultaneously carrying gaseous substrates to the enzyme while removing reaction products. In this system, interactions between the enzyme and non-reacting molecules are avoided, since no solvent is present, and it is thus more easy to assess the role of water. To this end, alcohol inhibition constant, substrates dissociation constants as well as acylation rate constant and ratio of acylation to deacylation rate constants have been determined as a function of water activity $\left(\mathrm{a}_{\mathrm{W}}\right)$. Data obtained highlight that $n$ propanol inhibition constant and dissociation constant of methyl propionate are a lot affected by $a_{W}$ variations whereas water has no significant effect on the catalytic acylation step nor on the ratio of acylation to deacylation rate constants. These results suggest the water independent character of the transition step.

\section{INTRODUCTION}

The activity of biocatalysts in non-conventional media, especially in organic solvents, is usually greatly affected by the level of water present in the medium. Numerous attempts have been made to investigate this dependence. As reported by many authors, water availability in non-conventional media cannot be quantified using its concentration because the capacity of organic phase to dissolve water varies considerably with the polarity of solvent. The influence of water is best analyzed in terms of its thermodynamic activity $\left(a_{w}\right)[1,2]$ and accurate comparisons of enzyme activity can only be made if water activity is controlled $[3,4,5]$.

For a majority of enzymes, the reaction rate is low or zero after exhaustive drying, but increases as slightly more water is present. This rise is considered to reflect a small quantity of water essential for enzyme activity, the hydration allowing to form the catalytic 
conformation [6]. It is clear that different biocatalysts require different levels of water to exhibit substantial activity. In particular, lipases from different sources differ considerably in their activity- $a_{w}$ profiles $[7,8]$. Some lipases show an activity optimum at very low water activity (Rhizopus arrhizus, Rhizopus niveus, Candida antarctica), some have increasing activity with increasing $\mathrm{a}_{\mathrm{W}}$ (Pseudomonas sp.), and others have intermediate profiles with broader optima (Mucor miehei and Candida rugosa).

As mentioned by many authors, the only way to assess the influence of water on enzyme kinetic behavior is to perform a full kinetic description based on properly determined $\mathrm{k}_{\mathrm{cat}}$ and $\mathrm{K}_{\mathrm{M}}$ values at different water activities [9]. Indeed it leads to the true maximal enzyme activity, and not substrate concentration-dependent activity.

Several authors studied the influence of water on the kinetic parameters of lipases in organic media, in the case of esterification or alcoholysis reactions, obeying Ping Pong $\mathrm{Bi} \mathrm{Bi}$ mechanism $[10,11,12]$. It was shown that water raises $K_{M}$ values for alcohol by acting as a competitive inhibitor of the nucleophile alcohol [10,11].

As far as the effect of water on the $\mathrm{K}_{\mathrm{M}}$ of acyl substrate is concerned, it was shown that, in the case of $R$. arrhizus lipase-catalyzed esterification, the $\mathrm{K}_{\mathrm{M}}$ for the acid presents no significant variation with $\mathrm{a}_{\mathrm{w}}$ [12]. The explanation was that this substrate binds to the enzyme first and does not compete with water in that sense. Nevertheless in an other study, increasing $a_{w}$ was shown to lead to an increase of the $\mathrm{K}_{\mathrm{M}}$ value for the acid in the case of esterification reaction [10]. The mechanism involved in this case was supposed to be a partial obstruction of the active site by water molecules binding close to it. Water was also shown to cause hydrophilic hindrance against hydrophobic substrates thereby inhibiting access to the enzyme [13].

Concerning the evolution of $\mathrm{k}_{\text {cat }}$ with $\mathrm{a}_{\mathrm{w}}$, it appears that $\mathrm{k}_{\text {cat }}$ generally increases with $\mathrm{a}_{\mathrm{w}}$ $[10,11,12]$. This corresponds to the activation of enzyme by hydration, involving a general role of water in making the enzyme structure more flexible and mobile, increasing the turnover rate. However high water levels have also been shown to reduce the rate of lipase- 
catalyzed esterification or transesterification [10,11]. This decline cannot be attributed to water competition with the alcohol because $\mathrm{k}_{\mathrm{cat}}$ is obtained at a saturating substrate concentration, but might be due to physical aggregation of enzyme, reducing interfacial area and limiting mass transfer $[8,11]$. To assess this hypothesis, a system in which aggregation plays a minor role, i.e. polyethylene glycol-modified lipase dispersed in toluene, was used. It was shown that $\mathrm{k}_{\text {cat }}$ increases continuously with $\mathrm{a}_{\mathrm{w}}$, the variation of $\mathrm{k}_{\text {cat }}$ as a function of $\mathrm{a}_{\mathrm{w}}$ resembling water adsorption isotherm for protein in organic solvent [11].

All these studies were performed in organic media, which makes the sole role of water impossible to assess. Indeed it was shown that at constant $\mathrm{a}_{\mathrm{w}}$, $\mathrm{k}_{\mathrm{cat}}$ varies with the organic solvent used, decreasing with increasing solvent hydrophobicity in the case of PEG-lipase catalyzed transesterification [11]. In several studies, it is shown that $\mathrm{K}_{\mathrm{M}}$ values obtained at constant $\mathrm{a}_{\mathrm{w}}$ in different organic solvents vary with the solvent used, but as they are expressed in molar concentration instead of thermodynamic activity, it is impossible to distinguish between the variation ascribed to different partitioning of the substrate and water between the enzyme and the organic phase or to the influence of the solvent alone [11]. In the study of Wehtje and Adlercreutz [12], $\mathrm{K}_{\mathrm{M}}$ obtained in different solvent were subjected to treatment with the UNIFAC group contribution method [14], to be expressed in thermodynamic activity, but this attempt failed to give adequate alignment of the $\mathrm{K}_{\mathrm{M}}$ in the different solvents. This would indicate that solvent has a proper effect on this parameter.

Contrary to the classical solid/organic liquid system, the solid/gas process offers several advantages to perform fundamental studies about the influence of water on biocatalysis. First in this system, the study is limited to the enzyme and the substrates/products/water since no species are predominant, contrary to synthesis in organic solvent. As a consequence, the role of water can be better assessed. Second it permits to perfectly control and adjust thermodynamic activities of reaction species [15]. 
In a previous paper, the alcoholysis of methyl propionate by 1-propanol using immobilized lipase B from Candida antarctica (CALB) as biocatalyst was studied in a solid/gas system. The kinetics obtained for alcoholysis were shown to fit a Ping Pong Bi Bi mechanism with dead-end inhibition by the alcohol [16]. The effect of water thermodynamic activity was also investigated. Water was found to act as a competitive inhibitor of methyl propionate, with a higher inhibition constant than n-propanol. This determination was obtained at fixed propanol thermodynamic activity, which does allow to assess adequately how water content affects the catalytic behavior of the enzyme in details. In this article, full kinetic studies of the alcoholysis of methyl propionate by 1-propanol using immobilized CALB as biocatalyst at water activities ranging from 0 to 0,3 are reported.

\section{EXPERIMENTAL}

\section{Enzyme and chemicals}

Chirazyme L2 (Type B lipase from Candida antarctica lyophilized) was a gift from Roche Industrie (Penzberg, Germany).

All esters of propionic acid (methyl-, ethyl-, propyl- and butyl propionate) were purchased from Fluka ( $\mathrm{S}^{\mathrm{t}} \mathrm{Quentin}-$ Fallavier, Switzerland). Propionic acid was from Sigma (St Louis, MO). All substrates were of the highest purity (99\% minimum) and checked by gas chromatography before use. Chemicals were dried over molecular sieves and filtered just before use. Pure water was obtained via a Milli Q system (Millipore, France).

\section{Adsorption of lipase onto a solid support}

Enzyme adsorption was performed onto Chromosorb P AW DMCS), mesh 60-80 (Acid Washed DiMethylChloroSilane) (Prolabo, France) as described in a previous work [16]. 


\section{Experimental setup for solid-gas catalysis}

The bioreactor used in this study has already been described in a previous publication [15]. The packed bed bioreactor itself was composed of a $9 \mathrm{~cm}$ long glass tube $(6.5 \mathrm{~mm}$ O.D., 3.5 mm I.D.) in which $15 \mathrm{mg}$ of the enzymatic preparation were packed between two glass wool layers. Substrate feeding was done by passing dried nitrogen, as carrier gas, through the substrate flasks. Substrates were continuously flowed through the bioreactor, reacting with the lipase. Thermodynamic activities of these compounds in the reactor are defined as the ratio of their partial pressure in gas entering the bioreactor to their saturation pressure at the working temperature. The desired thermodynamic activities of substrates were obtained by adjusting the volumetric flows of the carrier gas in the different lines at appropriate values, according to the calculations explained previously [15]. Calculations were performed considering that the gas was close to an ideal one. Then fugacity was not taken into account. The gas leaving the bioreactor was injected into a gas chromatograph for analysis. Acquisition and control of parameters (volumetric flows, molar flows, substrate and water thermodynamic activities, partial pressures, temperatures) were monitored on-line using an IBM personal computer. $\mathrm{a}_{\mathrm{E} 0}$ is the corrected thermodynamic activity of functional enzyme. It is defined as the product of a coefficient varying from 0 to 1 and $\mathrm{a}_{\mathrm{ET}}$, the thermodynamic activity of total enzyme. As the enzyme is in the solid state, $\mathrm{a}_{\mathrm{ET}}$ is by definition equal to 1 . The coefficient allows to correct $\mathrm{a}_{\mathrm{ET}}$ for modification of functional enzyme quantity.

A typical experiment was run at $70^{\circ} \mathrm{C}$, with $15 \mathrm{mg}$ of adsorbed enzyme and the total flow passing through the reactor was set at $1 \mathrm{mmol}^{\mathrm{min}}{ }^{-1}$ giving a volumetric flow of 28.5 mL.min ${ }^{-1}$. In these conditions, less than $5 \%$ of the substrates were converted allowing thus to assume that initial rates (expressed in $\mu$ moles of product formed per minute and per mg of enzymatic preparation) were measured and that inhibition by the products did not occur. 


\section{Chromatographic assays}

The vapor phase leaving the bioreactor was sampled using a $0.25 \mathrm{~mL}$ loop on a six-way valve (Valco) maintained at $150^{\circ} \mathrm{C}$. Samples were automatically injected in the split injector of a gas chromatograph (Hewlett Packard model 5890 A) equipped with a Flame Ionization Detector (FID) for detection of all products. The column used was a CP sil 19-CB fused silica capillary column (25 m x 0.32 mm i.d. x $1.2 \mu \mathrm{m}$ film thickness, Chrompack, France). The split ratio was $150: 1$. The injector and the detector were kept at $220^{\circ} \mathrm{C}$ and $250^{\circ} \mathrm{C}$ respectively. Carrier gas was nitrogen and the flow rate in the column was $2 \mathrm{~mL} \cdot \mathrm{min}^{-1}$. Hydrogen and air were supplied to the FID at 39 and $375 \mathrm{~mL} \cdot \mathrm{min}^{-1}$ respectively.

For the quantification of methanol, ethanol, propanol, methyl propionate, ethyl propionate, propyl propionate and propionic acid, the column temperature was held at $60^{\circ} \mathrm{C}$ for $1 \mathrm{~min}$., then programmed to increase at $3^{\circ} \mathrm{C} \cdot \mathrm{min}^{-1}$ to $80^{\circ} \mathrm{C}$.

For the quantification of butanol and butyl propionate, the column temperature was held at

$60^{\circ} \mathrm{C}$ for $1 \mathrm{~min}$., then programmed to increase at $3^{\circ} \mathrm{C} \cdot \mathrm{min}^{-1}$ to $70^{\circ} \mathrm{C}$ and at $5^{\circ} \mathrm{C} \cdot \mathrm{min}^{-1}$ from $70^{\circ} \mathrm{C}$ to $130^{\circ} \mathrm{C}$.

Quantitative data were obtained after integration on a HP 3396A integrator. An external standard method was used for the calculations.

\section{RESULTS}

\subsection{Stability of the enzyme in the solid/gas reactor}

As mentioned in a precedent study [16], it was checked that activity losses never exceed 5\% during experiment, the duration of which was inferior to 10 hours. 


\subsection{Determination of propanol inhibition constant and enzyme-substrate dissociation constants at different water thermodynamic activities}

As demonstrated in a previous work [16], the reaction of alcoholysis between methyl propionate and propanol catalyzed by CALB can be modelized by a Ping Pong Bi Bi mechanism with dead-end inhibition by the alcohol.

In this reaction sequence, the lipase reacts with methyl propionate to yield the lipase-methyl propionate complex or with propanol to yield a dead-end enzyme-propanol complex. Then the lipase-methyl propionate complex is transformed into an acyl-enzyme intermediate and the first product (methanol) is released. The second substrate, propanol, next interacts with the acyl-enzyme to form a ternary complex (Acyl-E-P), which finally yields propyl propionate and free lipase (scheme 1).

The kinetic rate expression for the Ping Pong Bi Bi mechanism of the lipase, considering that the experiments were performed under conditions in which the influence of the products can be neglected, can be written as shown in Equation (1).

At a given activity of propanol, equation 1 can be treated as an analog of the MichaelisMenten equation, with the apparent $\mathrm{V}_{\text {Mapp }}$ and $\mathrm{K}_{\text {Mapp }}$ being a function of $\mathrm{a}_{\mathrm{P}}$ (Equations 3 and 4). Experimental data (initial rates versus $\mathrm{a}_{\mathrm{MP}}$ at several $\mathrm{a}_{\mathrm{P}}$ values) were analyzed and gave $\mathrm{V}_{\text {Mapp }}$ and $\mathrm{K}_{\text {Mapp }}$ values for each $\mathrm{a}_{\mathrm{P}} . \mathrm{K}_{\mathrm{P}}$ and $\mathrm{K}_{\mathrm{MP}}$ were then determined using equations 3 and 4 as explained earlier [16]. Further details for the determination of dissociation constants $\left(\mathrm{K}_{\mathrm{I}}\right.$, $\mathrm{K}_{\mathrm{MP}}$ and $\mathrm{K}_{\mathrm{P}}$ ) are extensively detailed in a previous paper [16].

Wehtje and Adlercreutz [12] and Bovara et al. [11] have already applied this method for the calculation of $\mathrm{V}_{\mathrm{M}}$ and $\mathrm{K}_{\mathrm{M}}$ of acyl and alcohol substrates at different $\mathrm{a}_{\mathrm{W}}$, for esterification and transesterification reactions in organic media respectively.

Results are summarized in Table I. The variations of $K_{I}$ and $K_{M P}$ with $a_{W}$ follow the same trends, i.e. a slight decrease for $\mathrm{a}_{\mathrm{W}}$ comprised between 0 and 0.1 and a deep increase for $\mathrm{a}_{\mathrm{W}}$ superior to 0.1 . As far as $K_{P}$ is concerned, no significant deviation has been observed. 


\subsection{Inhibition studies using different chain lengths for linear primary alcohols}

The effect of the alcohol polarity on its inhibitory character $\left(\mathrm{K}_{\mathrm{I}}\right)$ at $\mathrm{a}_{\mathrm{W}}$ near 0 was also investigated using the same method as the one previously described. Typically, as deduced from equation 2, the dissociation constant of the alcohol-enzyme complex, $\mathrm{K}_{\mathrm{I}}$, can be deduced from the plot of $\mathrm{K}_{\mathrm{Mapp}} / \mathrm{V}_{\text {Mapp }}$ (obtained from the plot of reciprocal initial rates versus reciprocal $\mathrm{a}_{\mathrm{MP}}$ at different $\mathrm{a}_{\mathrm{P}}$ ) versus $\mathrm{a}_{\mathrm{P}}$ (Figure 1). $\mathrm{K}_{\mathrm{I}}$ values obtained for ethanol, propanol and butanol, ranging from 0.003 to 0.046 , showed that $\mathrm{K}_{\mathrm{I}}$ was increasing with chain length of the alcohol moiety. As water is not available, adsorption of alcohol molecules on the enzyme is likely to occur thus probably favoring the inhibitory effect for the most polar molecules.

\subsection{Determination of catalytic constants at different water thermodynamic activities}

A simplified kinetic scheme for the acyl-enzyme mechanism in the presence of an added nucleophile has been proposed by Garcia-Alles and Gotor [17] and is displayed on scheme 2. From this simplified mechanism, kinetic equations were determined using the steady state approach for the formation of the acyl-enzyme intermediate (Acyl-E). These equations enable catalytic constants at different water activities to be determined since they take into account the hydrolysis of methyl propionate even if the latter takes place in very particular conditions i.e. for very low thermodynamic activities of propanol $\left(\mathrm{a}_{\mathrm{p}}<0.05\right)$.

For kinetic experiments at $\mathrm{a}_{\mathrm{W}}$ superior to 0 (0.1 to 0.3$)$, the $\mathrm{a}_{\mathrm{W}}$ was set at a constant value and the initial rates of formation of propyl propionate $\left(\mathrm{Vi}_{\mathrm{PP}}\right)$ and propionic acid $\left(\mathrm{Vi}_{\mathrm{AP}}\right)$ were measured at different $\mathrm{a}_{\mathrm{MP}}$ values (0 to 0.25 ). From reciprocal initial rates versus reciprocal $\mathrm{a}_{\mathrm{MP}}$ plots, four apparent macroscopic rate constants $\left(\mathrm{V}_{\mathrm{Mapp}}\right)_{\mathrm{PP}},\left(\mathrm{V}_{\mathrm{Mapp}}\right)_{\mathrm{AP}},\left(\mathrm{K}_{\mathrm{Mapp}} / \mathrm{V}_{\mathrm{Mapp}}\right)_{\mathrm{PP}}$ and $\left(\mathrm{K}_{\mathrm{Mapp}} / \mathrm{V}_{\mathrm{Mapp}}\right)_{\mathrm{AP}}$ were extracted for each ap. The values of $\mathrm{V}_{\mathrm{M}}$ are not determined by the $y$ axis intercept at $1 / \mathrm{a}_{\mathrm{MP}}=0$, but rather by the $1 / \mathrm{V}$ value for $1 / \mathrm{a}_{\mathrm{MP}}=1$, since the maximum “substrate concentration” is 1 [16]. These experiments were repeated at several ap values 
(from 0.006 to 0.012 for the quantification of the propionic acid formation rate and up to 0.25 for the quantification of the propyl propionate formation rate). Then, for each $a_{w}$, 1/( $\left.\mathrm{V}_{\mathrm{Mapp}}\right)_{\mathrm{PP}}$ and $\left(1 / \mathrm{V}_{\mathrm{Mapp}}\right)_{\mathrm{AP}}$ values were plotted against 1/ap and ap respectively (Figure 2 and 3 respectively). These representations gave straight lines from which the slopes and the y-intercepts could be extracted using equations 7 and 9 giving $A(w), B(w), C$ and $D(w)$ values at each $a_{w}$. These experiments being run at fixed $a_{w}$ values, several parameter values $\left(\mathrm{k}_{2} \cdot \mathrm{a}_{\mathrm{E} 0}, \mathrm{k}_{2} / \mathrm{k}_{4}\right.$ and $\left.\mathrm{k}_{4} / \mathrm{k}_{3}\right)$ could be calculated for each $\mathrm{a}_{\mathrm{w}}$ (Table 2 ).

For $\mathrm{a}_{\mathrm{W}}$ equal to 0 , the sole product is propyl propionate at every ap value and the $1 / \mathrm{V}_{\mathrm{Mapp}}$ expression using the simplified mechanism is reduced to equation (11). So the y-intercept and the slope of the $1 / \mathrm{V}_{\text {Mapp }}$ versus $1 / \mathrm{a}_{\mathrm{P}}$ plot give directly $\left(\mathrm{k}_{2} \cdot \mathrm{a}_{\mathrm{E} 0}\right)^{-1}$ and $\left(\mathrm{k}_{4} \cdot \mathrm{a}_{\mathrm{E} 0}\right)^{-1}$. $\mathrm{k}_{2} \cdot \mathrm{a}_{\mathrm{E} 0}$ increases slightly for an $\mathrm{a}_{\mathrm{W}}$ increase from 0 to 0.1 , then decreases at $\mathrm{a}_{\mathrm{W}}=0.2$ to $\mathrm{a}$ similar value as the one observed without water. On the contrary, $\mathrm{k}_{2} \cdot \mathrm{a}_{\mathrm{E} 0}$ is divided by a factor 2 between $\mathrm{a}_{\mathrm{w}}$ values of 0.2 and 0.3 .

For $a_{\mathrm{p}}$ values higher than 0.05 , no hydrolysis of methyl propionate could be observed (no propionic acid formed) whatever $\mathrm{a}_{\mathrm{W}}$. Therefore, equation (10) enabled $\mathrm{K}_{\mathrm{S}} /\left(\mathrm{k}_{2} \cdot \mathrm{a}_{\mathrm{E} 0}\right)$ to be determined, giving finally $\mathrm{K}_{\mathrm{S}}$ (Table 2 ). $\mathrm{K}_{\mathrm{S}}$ values are not significantly different as the ones of $\mathrm{K}_{\mathrm{MP}}$. One can assume that both constants probably vary by change of $\mathrm{k}_{-1}$ which increases with $\mathrm{a}_{\mathrm{W}}$ (since $\mathrm{K}_{\mathrm{MP}}=\mathrm{K}_{\mathrm{S}}+\mathrm{k}_{2} / \mathrm{k}_{1}$ and $\mathrm{K}_{\mathrm{S}}=\mathrm{k}_{-1} / \mathrm{k}_{1}$ ) and that $\mathrm{k}_{2}$ and $\mathrm{k}_{1}$ are rather stable with $\mathrm{a}_{\mathrm{W}}$. Therefore, the variations of $\mathrm{k}_{2} \cdot \mathrm{a}_{\mathrm{E} 0}$ previously mentioned can be reasonably assigned to variations of functional enzyme quantity with $\mathrm{a}_{\mathrm{w}}$ rather than to variations of $\mathrm{k}_{2}$.

\section{DISCUSSION}

It was established that $\mathrm{K}_{\mathrm{I}}$ (propanol) and $\mathrm{K}_{\mathrm{MP}}$ decreased slightly when $\mathrm{a}_{\mathrm{W}}$ increases from 0 to 0.1. This can be related to the general water-induced enzyme activation, observed when biocatalysis is performed in anhydrous medium. Water would favor interaction between enzyme active site and ester or nucleophile inhibitor by acting as a molecular lubricant, 
increasing amino acid mobility [18] or increasing active site polarity [19]. To demonstrate the latter effect, Wangikar et al. [19] studied the combined effects of protein and solvent engineering using subtilisin from Bacillus amyloliquefaciens as a model serine protease. The effect of water in a polar (acetone) and apolar (hexane) solvent on catalytic efficiencies of a wild-type enzyme and two mutants was investigated for a transesterification reaction. One of the mutants named "polar mutant" presented a mutation in the back of the $\mathrm{S}_{1}$ acyl-binding pocket of the enzyme (Gly ${ }_{166}$-Asn). It was shown that in hexane the increased polarity of the "polar mutant" improved the interaction of the enzyme with polar substrate, which is expected to take place mainly in the $S_{1}$ subsite of subtilisin. In the presence of small concentrations of water added, however, this advantage over the wild-type enzyme was made negligible, presumably by polar water molecules penetrating into the active site of the enzyme.

When $a_{w}$ is increased from 0,1 to 0,3 , the opposite effect is obtained, i.e. both constants increase significantly. Water would thus affect enzyme-methyl propionate and enzymepropanol interactions. This is in accordance with our previous results [16], which stated that water acted predominantly as a competitive inhibitor of methyl propionate, after optimal hydration level for catalysis was reached $\left(a_{w}>0,1\right)$. Water would bind close to the active site to form a dead-end complex, as the alcohol inhibitor does too.

The effect of water on $\mathrm{K}_{\mathrm{I}}$ (propanol) would account for mutual exclusivity of the two competitive inhibitors close to the active site. Indeed it was shown that propanol is able to compete with water for the adsorption at hydration sites of proteins, in particular at ionizable groups at the surface of the protein [20]. In principle, the precise dependence of binding constant of propanol to enzyme on $\mathrm{a}_{\mathrm{w}}$ gives an estimate of the number of water molecules displaced, though a mass action relationship. Valivety et al. made such an estimate in case of esterification of dodecanol and decanoic acid in hexane catalyzed by lipases at different $\mathrm{a}_{\mathrm{W}}$, where water and acid were in competition for binding to the active site [10]. They estimated the number of water molecules displaced by acid substrate, by using substrate dissociation 
constant values at two different $\mathrm{a}_{\mathrm{W}}$, instead of binding constants of acid to enzyme at different $\mathrm{a}_{\mathrm{W}}$. In table 1, it appears that $\mathrm{K}_{\mathrm{I}}$ (propanol) changes 6 fold with a 2 fold change in $\mathrm{a}_{\mathrm{w}}$ (when $\mathrm{a}_{\mathrm{W}}$ increases from 0,1 to 0,2 ), This could be accounted for if 3 water molecules were displaced per alcohol molecule. When $\mathrm{a}_{\mathrm{W}}$ increases from 0,1 to $0,3, \mathrm{~K}_{\mathrm{I}}$ (propanol) is multiplied by a factor 18, which corresponds this time to the displacement of 6 water molecules per alcohol molecule. Therefore an additional effect of water on $\mathrm{K}_{\mathrm{I}}$ (propanol) could be assumed: the possible formation of a solvent barrier of water molecules at a key position near the enzyme. Indeed, if the use of thermodynamic activities (instead of concentrations) is a method allowing correction for substrate availability at different hydration conditions, it does not permit to account for the differences between enzyme-water and enzyme-substrate interactions [21].

Moreover it has to be pointed out that at an $\mathrm{a}_{\mathrm{W}}$ close to zero, $\mathrm{K}_{\mathrm{I}}$ (propanol) is almost ten times higher in the organic medium than in the gas phase (Table I). One can suppose that 2-methyl 2-butanol, which is a moderately polar tertiary alcohol, is likely to interact with the protein and to shield enzyme from other species, as water does, thereby limiting the access of propanol to the active site [21]. Besides, the value obtained for $\mathrm{K}_{\mathrm{I}}$ (propanol) in the organic medium without water is similar to the one obtained in the gas phase at $a_{\mathrm{W}}$ equal to 0,3 (Table1). 2-Methyl 2-butanol might even act as a competitive inhibitor of methyl propionate, as propanol and water do, which would account for the higher values of $K_{I}$ and $K_{M P}$ in the organic phase compared to the ones in the gas phase. Van Tol et al. [22] also suggested a competitive inhibition of the solvent by non-specific interactions of the solvent and the active site.

With regard to the increase of $\mathrm{K}_{\mathrm{MP}}$ when $\mathrm{a}_{\mathrm{W}}$ increases from 0,1 to 0,3 , the same explanation can be put forward for the role of water on the binding of the ester first substrate on the enzyme, i. e. the formation of an hydrophilic barrier in the vicinity of the active site, hindering the access to it. 
Garcia-Alles and Gotor [17] studied the kinetics of immobilized CALB-catalyzed transesterification in non-aqueous organic media. They measured how the solvent affects the first substrate (ester) binding constant and the nucleophile inhibition constant independently. It was first established that the support did not interfere with solvent effects on the enzyme and that the catalytic mechanism seemed to be the same regardless of the solvent used, i.e. Ping Pong Bi Bi with acyl-enzyme intermediate. It was shown that the binding and inhibition constants were significantly increased when the polarity of the solvent increased; these variations could not be explained using thermodynamic arguments (solvation of the ester or the inhibitor). The solvent itself could thus lead to a decrease of the affinity between enzyme and ester or nucleophile by an other effect than solvation of these molecules, like direct hindrance effect of the active site for example. It was shown that this effect increases with the polarity of the solvent.

Moreover in an other study, it was found that the binding of ester and alcohol to CALB was lower in polar acetonitrile than in apolar heptane and that these differences could not be explained by the difference in solvation of the substrates by the solvents [23]. The possible explanation proposed was that acetonitrile interacts more strongly than heptane with the active site and thereby increases the $\mathrm{K}_{\mathrm{M}}$ value of the substrates.

The effect of the alcohol polarity on its inhibitory character was investigated and it appears that the more hydrophobic the alcohol is, the higher the $\mathrm{K}_{\mathrm{I}}$ (alcohol) value is. Garcia-Alles and Gotor [24] also related an increased inhibitory effect of short chain alcohols for alcoholysis of ethylacetate catalyzed by CALB in anhydrous cyclohexane. In an other study, an explanation for higher inhibitory effect of short chain alcohols is that they increase the system polarity thereby shifting the water distribution towards the fluid phase (supercritical CO2) which results in the removal of essential water molecules from the immobilized enzyme [25]. Another possible explanation is that polar molecules such as water or short chain alcohols may bind close to the active site and form an hydrophilic barrier impeding the 
binding of the acyl substrate. The hydroxyl of the alcohol or of water may bind to the region around the catalytic serine (Ser-105) which has been reported to be polar in nature [26].

This latter hypothesis is supported by our results concerning the effect of water on $\mathrm{K}_{\mathrm{I}}$ of the alcohol since a possible explanation for mutual exclusivity of the two competitive inhibitors is that they compete for the same site on the enzyme suggesting they interacts with the enzyme with the same type of interaction, i.e. polar interactions.

The effect of $a_{W}$ on $K_{P}$ (dissociation constant of the acyl-enzyme-propanol complex) was found to be negligible, which is opposite to results obtained by several authors in organic medium. Indeed, several studies report that the $\mathrm{K}_{\mathrm{M}}$ for the second substrate alcohol increases with $a_{W}$, in case of esterification catalyzed by different lipases [10,12]. In the present case, the fact that $\mathrm{K}_{\mathrm{P}}$ is not influenced by $\mathrm{a}_{\mathrm{W}}$ seems to mean that the second step of the reaction (deacylation) is not influenced by the microenvironment contrary to the first step (acylation step) which is both influenced by the water activity (increase of $K_{I}$ and $K_{M P}$ with $a_{W}$ for $a_{W}$ superior to 0.1 ) and the medium (gas or organic phase). Indeed, $K_{I}$ and $K_{M P}$ are more than ten times lower in the gas phase than in the organic phase at $a_{W}$ near 0 , contrary to $K_{P}$ which is the same in both media. One can suppose from this last result that the first step of the reaction (acylation or nucleophile inhibition) takes place with substrates or more generally species in the gas state whereas the acyl-enzyme intermediate would happen in a "pseudoliquid state”, after condensation of substrates molecules through binding with the enzyme. Further experiments could be run in the gas phase to determine dissociation constants in the presence of increasing thermodynamic activities of 2-methyl 2-butanol or of an inert solvent. Concerning the influence of $\mathrm{a}_{\mathrm{w}}$ on the catalytic acylation rate $\left(\mathrm{k}_{2}\right)$, it was shown that a small quantity of water added $\left(a_{w}=0,1\right)$ leads to a small increase of $k_{2} a_{E 0}$. This is consistent with an increase of active-site flexibility and as a result, flexibility of the enzymic transition state afforded by water. In the previously mentioned study [19], it was shown that a small quantity of water added (5\% in anhydrous THF) resulted in an increase in the rate constant of 
acylation for subtilisin-catalyzed transesterification. This increase was more pronounced for the wild-type enzyme than for the "polar mutant". It was suggested that, in addition to its role of plasticizer, water can increase the proton conductivity within an enzyme. Serine proteases utilize general acid-base catalysis and proton transfer to the catalytic histidine has been suggested to be rate-limiting during acylation [27]. In the present study, water would thus increase this proton-transfer rate and increase the $\mathrm{k}_{2}$ value.

When $\mathrm{a}_{\mathrm{w}}$ is increased from 0,1 to 0,3 , the opposite effect is obtained, i.e. $\mathrm{k}_{2} \cdot \mathrm{a}_{\mathrm{E} 0}$ decreases. As explained in the results section, this latter effect could be assigned to a decrease of functional enzyme quantity, rather than to a decrease of $\mathrm{k}_{2}$. This could be proved by active site titration at different $\mathrm{a}_{\mathrm{w}}$, but available methods for this titration need to be performed in organic solvents and it was shown that solvents have an influence on this parameter [19, 24].

The influence of the polarity of organic solvent on individual rate constants in the case of transesterification of ethyl acetate and $n$-butanol catalyzed by immobilized CALB was studied by Garcia-Alles and Gotor [17]. It was found that changes on acylation rate and deacylation rate were much less important than the variations of substrate binding with the solvent, indicating that the organic solvent almost did not interfere with enzyme-transition state interactions. Furthermore the ratio of these two rates was found to be independent on the polarity of the solvent used, which was interpreted as an indication of the transition-state desolvation. In the present study, this ratio $\left(\mathrm{k}_{2} / \mathrm{k}_{4}\right)$ is almost constant for $\mathrm{a}_{\mathrm{W}}$ equal to $0,0,1$ and 0,2 (Table 2), as if acyl-enzyme intermediate was shielded from its microenvironment. To conclude, the results obtained in the present study highlight that water may play multiple roles in the enzyme's active site, either directly or indirectly. This work provides more evidence that enzyme hydration is a complex phenomenon.

As demonstrated in this work, water affects mainly the first step of the reaction, i.e. the acylation step, by increasing the dissociation constants between both enzyme and acyl substrate and enzyme and alcohol. It was suggested that water, as polar alcohols, binds to the 
enzyme through polar interactions and thereby blocks the access to the active site. However, water has no significant effect on the catalytic constant $k_{2}$. Once the acyl-enzyme intermediate has been formed, water does not seem to have an influence anymore on the binding of the second substrate nor on the catalytic constant of deacylation. Similar results have been reported in the literature concerning the independence of deacylation on $\mathrm{a}_{\mathrm{w}}$ and solvent polarity. Results suggest that addition of water in the solid/gas reactor mimicks an increase of solvent polarity in organic media. Further experiments are in progress to evaluate the effect of solvent of different polarities on kinetic parameters in the solid/gas reactor. 


\section{REFERENCES}

[1]- Halling, P.J. (1987) Water activity in biphasic reaction systems. In Biocatalysis in organic media, Laane C., Tramper J., Lilly M.D. (Eds), Elsevier Science Publishers, Amsterdam, 125132.

[2]- Cassels, J.M. and Halling, P.J. (1988) Effect of thermodynamic water activity on thermolysin-catalysed peptide synthesis in organic two-phase systems. Enzyme Microb. Technol., 10, 486-491.

[3]- Goldberg, M., Parvaresh, F., Thomas, D. and Legoy, M.D. (1988) Enzymatic ester synthesis with continuous measurement of water activity. Biochim. Biophys. Acta., 957, 359362.

[4]- Goldberg, M., Thomas, D. and Legoy, M.D. (1990) Water activity as a key parameter in synthesis reactions : the lipase example. Enzyme Microb. Technol., 12, 976-981.

[5]- Ljunger, G., Adlercreutz, P. and Mattiasson, B. (1994) Enzymatic synthesis of octyl- $\beta$-Dglucoside in octanol at controlled water activity. Enzyme Microb. Technol., 16, 751-755.

[6]- Rupley, J.A., Gratton, E. and Careri G. (1983) Water and globular proteins. Trends Biochem. Sci., 8, 18-22.

[7]- Valivety, R.H., Halling, P.J. and Macrae, A.R. (1992) Lipases from different sources vary widely in dependence of catalytic activity on water activity. Biochim. Biophys. Acta, 1122, 143-146.

[8]- Valivety, R.H., Halling, P.J. and Macrae, A.R. (1992) Reaction rate with suspended lipase catalyst shows similar dependence on water activity in different organic solvents. Biochim. Biophys. Acta, 1118, 218-222.

[9]- Van Erp, S.H.M., Kamenskaya, E.O. and Khmelnitsky, Y.L. (1991) The effect of water content and nature of organic solvent on enzyme activityin low-water media. Eur. J. Biochem., 202, 379-384. 
[10]- Valivety, R.H., Halling, P.J. and Macrae, A.R. (1993) Water as a competitive inhibitor of lipase-catalysed esterification in organic media. Biotechnol. Lett., 15, 1133-1138.

[11]- Bovara, R., Carrea, G., Ottolina, G. and Riva, S. (1993) Effects of water activity on $V_{\max }$ and $\mathrm{K}_{\mathrm{M}}$ of lipase catalyzed transesterification in organic media. Biotechnol. Lett., 15, 937942.

[12]- Wehtje, E. and Adlercreutz, P. (1997) Water activity and substrate concentration effects on lipase activity. Biotechnol. Bioeng., 55, 798-806.

[13]- Marty, A., Chulalaksananukul, W., Willemot R.M. and Condoret J.S. (1992) Kinetics of lipase-catalyzed esterification in supercritical $\mathrm{CO}_{2}$. Biotechnol. Bioeng., 39, 273-280.

[14]- Hansen, H.K., Rasmussen, P., Fredenslund, A., Schiller, M. and Gmehling, J. (1991) Ind. Eng. Chem. Res. 30: 2355-2358.

[15]- Lamare, S. and Legoy, M.D. (1995) Working at controlled water activity in a continuous process: The gas/solid system as a solution. Biotechnol. Bioeng., 45, 387-397.

[16]- Bousquet-Dubouch M. P., Graber M., Sousa N., Lamare S. and Legoy M. D. (2001) Alcoholysis catalysed by Candida antarctica lipase B in a gas/solid system obeys a Ping Pong Bi Bi mechanism with competitive inhibition by the alcohol substrate and water. Biochim. Biophys. Acta, 1550, 90-99.

[17]- Garcia-Alles L.F. and Gotor V. (1998a) Lipase-catalyzed tranesterification in organic media : solvent effects on equilibrium and individual rate constants. Biotechnol. Bioeng 59: 684-694.

[18] Schmitke J.L., Wescott C.R., Klibanov A.M. (1996) The mechanistic dissection of the plunge in enzymatic activity upon transition from water to anhydrous solvents. J. Am. Chem. Soc. 118: 3360-3365.

[19]- Wangikar P.P., Graycar T.P., Estell D.A., Clark D.S. and Dordick J.S. (1993) Protein and solvent engineering of subtilisin BPN'in nearly anhydrous organic media. 115: 1223112237. 
[20]- Mc Minn, J.H., Sowa, M.J., Charnick, S.B. and Paulaitis, M.E. (1993) The hydration of proteins in nearly anhydrous organic solvent suspensions. Biopolymers 33, 1213-1224.

[21]- Graber M., Bousquet-Dubouch M. P., Sousa N., Lamare S. and Legoy M. D. (2003). Water plays a different role on activation thermodynamic parameters of alcoholysis reaction catalyzed by Lipase in gaseous and organic media. Biochim. Biophys. Acta, in press.

[22]- Van Tol, J.B.A., Kraayveld, D.E., Jongejan, J.A. and Duine, J.A. (1995) The catalytic performance of pig pancreas lipase in enantioselective transesterification in organic solvents. Biocatal. Biotrans. 12: 119-136.

[23]- Martinelle, M. and Hult, K. (1995) Kinetics of acyl transfer reactions in organic media catalysed by Candida antarctica lipase B. Biochim. Biophys. Acta. 1251: 191-197.

[24]- Garcia-Alles L.F. and Gotor V. (1998b) Alcohol inhibition and specificity studies of lipase B from Candida antarctica in organic solvents. Biotech. Bioeng. 59: 163-170. [25]- Goddard, R., Bosley, J. and Al-Duri, B. (2000) Esterification of oleic acid and ethanol in plug flow (packed bed) reactor under supercritical conditions - Investigation of kinetics. J. of Supercritical Fluids 18: 121-130

[26]- Uppenberg J., Öhrner N., Norin M., Hult K., Kleywegt G.J., Patkar S., Waagen V., Anthonsen T. and Jones T.A. (1995) Crystallographic and molecular modelling studies of lipase B from Candida antarctica reveal a stereospecificity pocket for secondary alcohols. Biochemistry. 34 : 16838-16851.

[27]- Careri G., Geraci M., Giansanti A. and Rupley J.A. (1985) Protonic conductivity of hydrated lysozyme powder at megahertz frequencies. Proc. Natl. Acad. Sci. U.S.A. 82: 5342-5346. 


\section{FIGURE LEGEND}

\section{Figure 1}

Determination of the dissociation constant of the enzyme-alcohol complex $\left(\mathrm{K}_{\mathrm{I}}\right)$ in the solid/gas bioreactor for 3 aliphatic alcohols using equation (2)

\section{Figure 2}

Reciprocal $\mathrm{V}_{\text {Mapp }}$ versus reciprocal ap at different $\mathrm{a}_{\mathrm{W}}$ values.

$\mathrm{V}_{\text {Mapp }}$ were obtained from the plot of reciprocal initial rates of formation of propyl propionate versus reciprocal $\mathrm{a}_{\mathrm{MP}}(0$ to 0.25$)$ at different $\mathrm{a}_{\mathrm{P}}(0.006$ to 0.25$)$ and for each $\mathrm{a}_{\mathrm{W}}$ (0 to 0.3$)$.

Synthesis was carried out in the solid/gas bioreactor at $70^{\circ} \mathrm{C}$, at a molar flow of 1 mmol.min ${ }^{-1}$ in the presence 5 to $15 \mathrm{mg}$ of adsorbed CALB onto Chromosorb AW DMCS.

\section{Figure 3}

Reciprocal $\mathrm{V}_{\text {Mapp }}$ versus ap at different $\mathrm{a}_{\mathrm{w}}$ values.

$\mathrm{V}_{\text {Mapp }}$ were obtained from the plot of reciprocal initial rates of formation of propionic acid versus reciprocal $\mathrm{a}_{\mathrm{MP}}(0$ to 0.25$)$ at different $\mathrm{a}_{\mathrm{P}}(0.006$ to 0.25$)$ and for each $\mathrm{a}_{\mathrm{W}}(0$ to 0.3$)$. Synthesis was carried out in the solid/gas bioreactor at $70^{\circ} \mathrm{C}$, at a molar flow of 1 mmol.min ${ }^{-1}$ in the presence 5 to $15 \mathrm{mg}$ of adsorbed CALB onto Chromosorb AW DMCS. 


\section{SCHEME 1}

$$
\begin{aligned}
& \mathrm{EP} \\
& \mathrm{P} \| \mathrm{K}_{\mathrm{I}} \\
& \mathrm{E}+\mathrm{MP} \underset{\mathrm{k}_{-1}}{\stackrel{\mathrm{k}_{1}}{\rightleftharpoons}} \text { E-MP } \underset{\mathrm{M}}{\stackrel{\mathrm{k}_{2}}{\longrightarrow}} \text { Acyl-E } \stackrel{\mathrm{k}^{\prime}{ }_{1 . \mathrm{a}_{\mathrm{P}}}}{\rightleftharpoons} \text { Acyl-E-P } \stackrel{\mathrm{k}_{-1}{ }_{2}}{\longrightarrow} \mathrm{E}+\mathrm{PP}
\end{aligned}
$$

$$
V i=\frac{V_{\text {Mapp }} \cdot a_{M P}}{K_{\text {Mapp }}+a_{M P}}(1)
$$

$$
\text { with }\left\{\begin{array} { l } 
{ \frac { K _ { \text { Mapp } } } { V _ { \text { Mapp } } } = \frac { K _ { M P } } { V _ { M } } ( 1 + \frac { a _ { P } } { K _ { I } } ) ( 2 ) } \\
{ V _ { \text { Mapp } } = \frac { a _ { P } \cdot V _ { M } } { K _ { P } + a _ { P } } \Leftrightarrow V _ { \text { Mapp } } = - ( K _ { P } \cdot V _ { \text { Mapp } } / a _ { P } ) + V _ { M } ( 3 ) } \\
{ K _ { \text { Mapp } } = K _ { M P } \cdot \frac { a _ { P } \cdot ( 1 + a _ { P } / K _ { I } ) } { K _ { P } + a _ { P } } ( 4 ) }
\end{array} \quad \text { and } \quad \left\{\begin{array}{l}
\mathrm{K}_{\mathrm{MP}}=\frac{k_{-1}+k_{2}}{k_{1}}, \\
\mathrm{~K}_{\mathrm{P}}=\frac{k_{-1}^{\prime}+k_{2}^{\prime}}{k_{1}^{\prime}},
\end{array}\right.\right.
$$

$\mathrm{E}=$ enzyme, $\mathrm{MP}=$ methyl propionate, $\mathrm{P}=$ propanol, $\mathrm{M}=$ methanol, $\mathrm{PP}=$ propyl propionate $\mathrm{a}_{\mathrm{P}}$ and $\mathrm{a}_{\mathrm{MP}}$ are thermodynamic activities of propanol and methyl propionate respectively and $\mathrm{K}_{\mathrm{I}}, \mathrm{K}_{\mathrm{MP}}$ and $\mathrm{K}_{\mathrm{P}}$ are the dissociation constants of the propanol-enzyme, enzyme-methyl propionate and acyl-enzyme-propanol complexes respectively. 
SCHEME 2

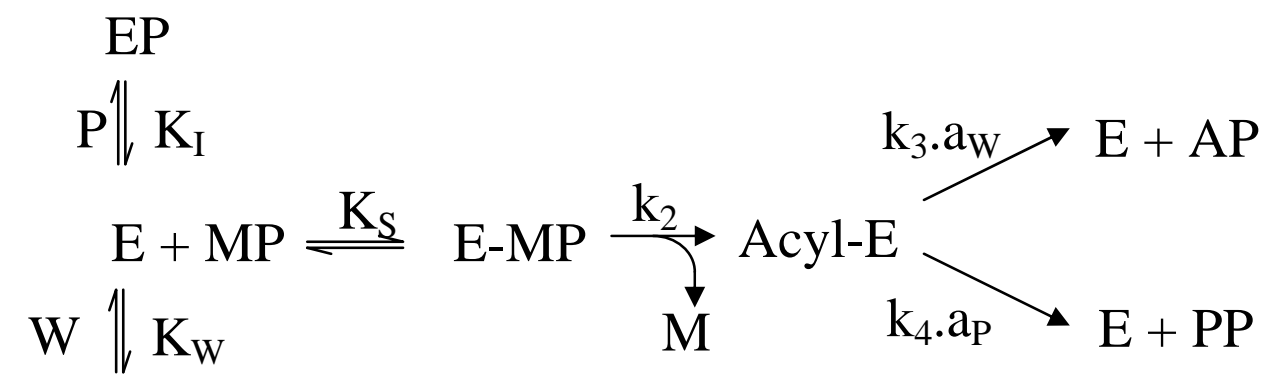

EW

$\left(\frac{1}{V_{i}}\right)_{P P, A P}=\left(\frac{K_{\text {Mapp }}}{V_{\text {Mapp }}}\right)_{P P, A P} \cdot \frac{1}{a_{M P}}+\left(\frac{1}{V_{\text {Mapp }}}\right)_{P P, A P}$

(Equation 5)

with

If aw $>0$

$$
\begin{aligned}
& \left\{\begin{array}{l}
\left(\frac{K_{\text {Mapp }}}{V_{\text {Mapp }}}\right)_{A P}=\left(1+\frac{a_{P}}{K_{I}}+\frac{a_{W}}{K_{W}}\right) \cdot\left(\frac{K_{S}}{k_{2} \cdot a_{E_{0}}}+\frac{K_{S} \cdot k_{4}}{k_{2} \cdot a_{E_{0}} k_{3} a_{W}} \cdot a_{P}\right) \quad \text { (Equation 6) } \\
\left(\frac{1}{V_{\text {Mapp }}}\right)_{A P}=\frac{k_{2}+k_{3} \cdot a_{W}}{k_{2} \cdot a_{E_{0}} k_{3} a_{W}}+\frac{k_{4}}{k_{2} \cdot a_{E_{0}} k_{3} a_{W}} \cdot a_{P}=A(w)+B(w) \cdot a_{P} \quad \text { (Equation 7) }
\end{array}\right. \\
& \left\{\begin{array}{l}
\left(\frac{K_{\text {Mapp }}}{V_{\text {Mapp }}}\right)_{P P}=\left(1+\frac{a_{P}}{K_{I}}+\frac{a_{W}}{K_{W}}\right) \cdot\left(\frac{K_{S}}{k_{2} \cdot a_{E_{0}}}+\frac{K_{S} \cdot k_{3} \cdot a_{W}}{k_{2} \cdot k_{4} a_{E_{0}}} \cdot \frac{1}{a_{P}}\right) \quad \text { (Equation 8) } \\
\left(\frac{1}{V_{\text {Mapp }}}\right)_{P P}=\frac{1}{k_{2} \cdot a_{E_{0}}}+\frac{k_{2} k_{3} a_{W}}{k_{2} \cdot k_{4} a_{E_{0}}} \cdot \frac{1}{a_{P}}=C+D(w) \cdot \frac{1}{a_{P}} \quad \text { (Equation 9) }
\end{array}\right.
\end{aligned}
$$

If $\mathrm{aw}=0$

$$
\begin{cases}\left(\frac{K_{\text {Mapp }}}{V_{\text {Mapp }}}\right)_{P P}=\frac{K_{S}}{k_{2} \cdot a_{E_{0}}} \cdot\left(1+\frac{a_{P}}{K_{I}}\right) & (\text { Equation 10) } \\ \left(\frac{1}{V_{\text {Mapp }}}\right)_{P P}=\frac{1}{k_{4} \cdot a_{E_{0}}} \cdot \frac{1}{a_{P}}+\frac{1}{k_{2} \cdot a_{E_{0}}} & \text { (Equation 11) }\end{cases}
$$


Table I : Effect of $\mathrm{a}_{\mathrm{W}}$ on dissociation constants of propanol-enzyme, enzyme-methyl propionate and acyl-enzyme-propanol complexes respectively $\left(\mathrm{K}_{\mathrm{I}}, \mathrm{K}_{\mathrm{MP}}\right.$ and $\left.\mathrm{K}_{\mathrm{P}}\right)$ and on $\mathrm{V}_{\mathrm{M}}$

\begin{tabular}{|c|c|c|c|c|}
\cline { 2 - 5 } \multicolumn{1}{c|}{} & $\mathrm{a}_{\mathrm{W}}$ & $\mathrm{K}_{\mathrm{I}}$ & $\mathrm{K}_{\mathrm{MP}}$ & $\mathrm{K}_{\mathrm{P}}$ \\
\hline \multirow{3}{*}{ Gas phase } & 0 & 0.019 & 0.047 & 0.022 \\
\cline { 2 - 5 } & 0.1 & 0.009 & 0.009 & 0.015 \\
\cline { 2 - 5 } & 0.2 & 0.052 & 0.044 & 0.021 \\
\cline { 2 - 5 } & 0.3 & 0.161 & 0.161 & 0.013 \\
\hline Organic phase $^{*}$ & 0 & 0.160 & 0.651 & 0.020 \\
\hline
\end{tabular}

* results from Bousquet-Dubouch et al. [16]

Table II : Effect of $\mathrm{a}_{\mathrm{W}}$ on catalytic constants

\begin{tabular}{|c|c|c|c|c|}
\hline $\mathrm{a}_{\mathrm{W}}$ & $\mathrm{k}_{2} \cdot \mathrm{a}_{\mathrm{E} 0}\left(\mathrm{~min}^{-1}\right)$ & $\mathrm{k}_{2} / \mathrm{k}_{4}$ & $\mathrm{k}_{4} / \mathrm{k}_{3}$ & $\mathrm{~K}_{\mathrm{S}}$ \\
\hline 0 & 0.49 & 0.013 & n.d. & 0.037 \\
\hline 0.1 & 0.56 & 0.014 & 91.8 & 0.015 \\
\hline 0.2 & 0.45 & 0.010 & 55.1 & 0.060 \\
\hline 0.3 & 0.22 & n.d. & 51.6 & 0.131 \\
\hline
\end{tabular}


FIGURE 1

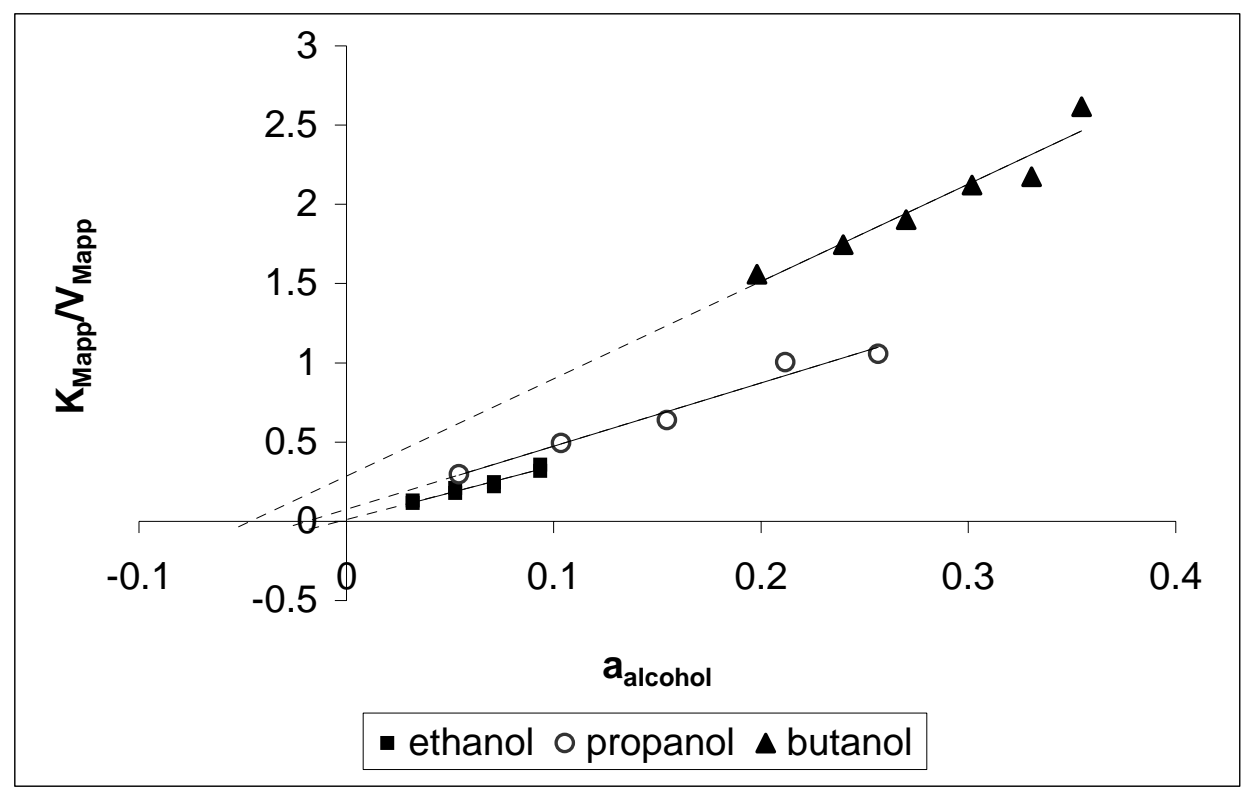


FIGURE 2

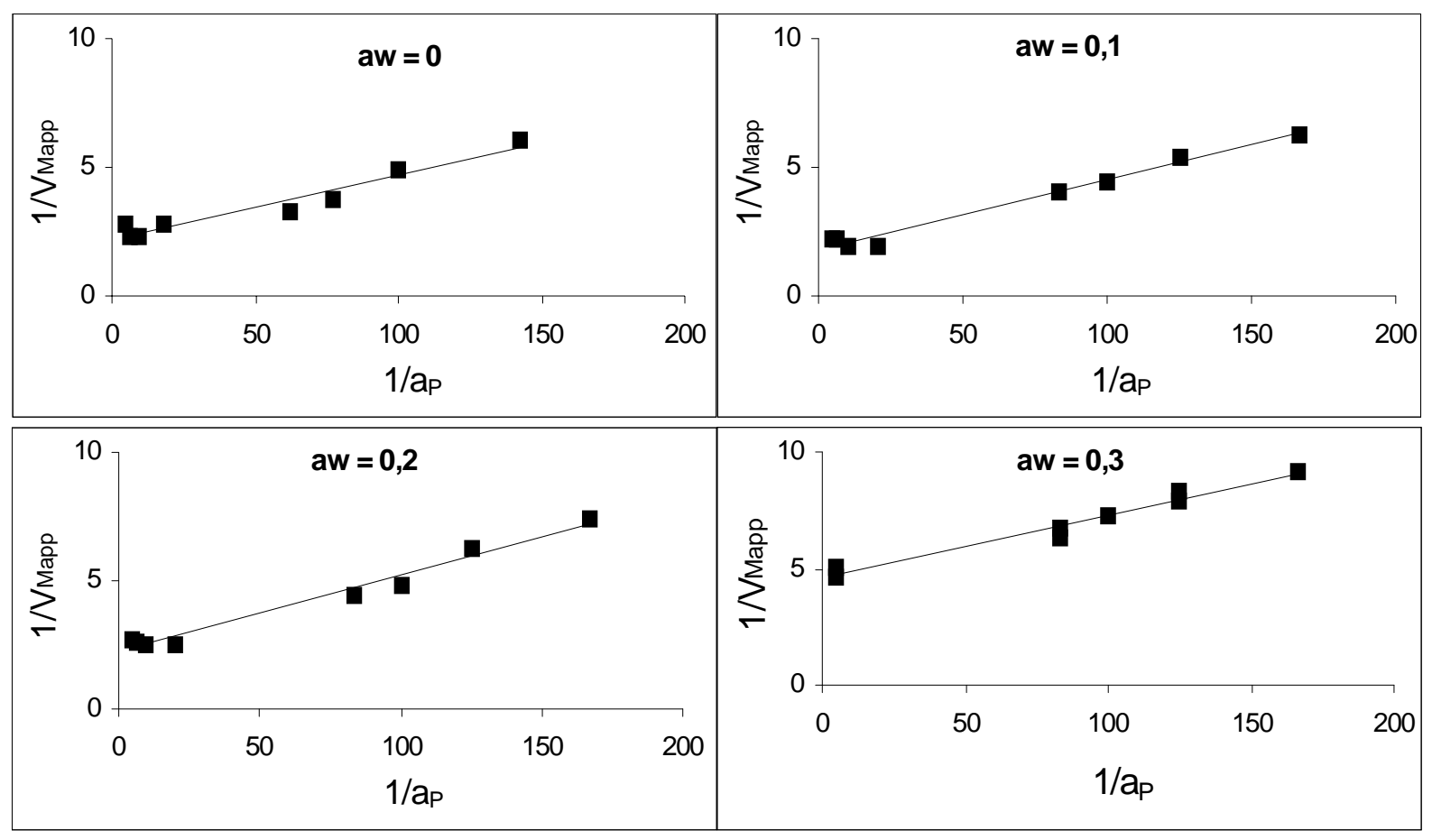


FIGURE 3

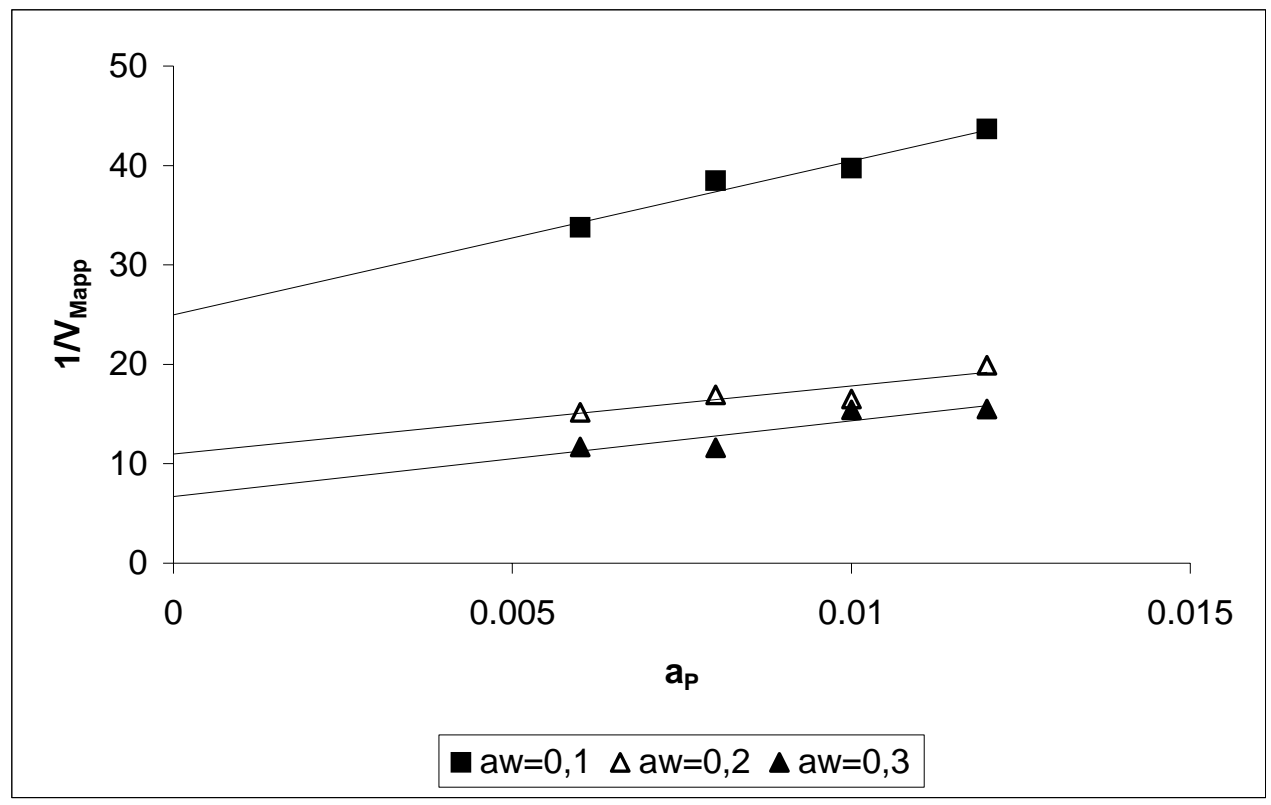

